\title{
Chromosomal Location and Mapping of Quantitative Trait Locus Determining Technological Parameters of Grain and Flour in Strong-flour Bread Wheat Cultivar Saratovskaya 29
}

\author{
L.V. Shchumina ${ }^{1 *}$, T.A. Pshenichnikova ${ }^{1}$, E.K. KhlestKina ${ }^{1,2}$, S. Misheva ${ }^{3}$, T. Kartseva ${ }^{3}$, \\ A. ABUgalieva ${ }^{4}$ and A. BöRNER ${ }^{5}$ \\ ${ }^{1}$ The Federal Research Center "Institute of Cytology and Genetics", \\ Siberian Branch of the Russian Academy of Sciences, pr. Lavrentieva, 10, Novosibirsk, 60090, Russia \\ ${ }^{2}$ N.I. Vavilov All-Russian Research Institute of Plant Genetic Resources, \\ ul. Bolshaya Morskaya, 44, Saint-Petersburg, 190000, Russia \\ ${ }^{3}$ Institute of Plant Physiology and Genetics, Bulgarian Academy of Sciences, \\ Acad. G. Bonchev str., bl. 21, 1113 Sofia, Bulgaria \\ ${ }^{4}$ Kazakh Scientific Research Institute of Agriculture and Plant Growing, Almaty region, Karasay district, \\ Almalybak village, Erlepesova street, 1, 040909, Republic of Kazakhstan \\ ${ }^{5}$ Leibniz-Institut für Pflanzengenetik und Kulturpflanzenforschung (IPK), \\ Corrensstr. 3, 06466 Stadt Seeland, OT Gatersleben, Germany
}

(Received 14 March 2018; Accepted 26 June 2018; Communicated by F. Békés)

\begin{abstract}
Bread wheat is the primary bread crop in the majority of countries in the world. The most important product that is manufactured from its grain and flour is yeast bread. In order to obtain an excellent bread, grain with high physical properties is needed for flour and dough. The Russian spring wheat cultivar Saratovskaya 29 is characterized by its exclusively high physical properties of flour and dough. The purpose of this work was to identify the chromosomes carrying the main loci for these traits in Saratovskaya 29 and to map them using recombinant substitution lines genotyped with molecular markers. A set of inter-varietal substitution lines Saratovskaya 29 (Yanetzkis Probat) was used to identify the "critical" chromosomes. The donor of individual chromosomes is a spring cultivar with average dough strength and tenacity. Substitution of $1 \mathrm{D}$ and $4 \mathrm{D}^{*} 7 \mathrm{~A}$ chromosomes in the genetic background of Saratovskaya 29 resulted in a significant decrease in the physical properties of the dough. Such a deterioration in the case of $1 \mathrm{D}$ chromosome might be related to the variability of gluten protein composition. With the help of recombinant substitution double haploid lines obtained from a Saratovskaya 29 (Yanetzkis Probat 4D*7A) substitution line the region on the 4D chromosome was revealed in the strong-flour cultivar Saratovskaya 29, with the microsatellite locus $\mathrm{Xgwm0165}$ to be associated with the unique physical properties of flour and dough. The detected locus is not related to the composition gluten proteins. These locus may be recommended to breeders for the selection of strong-flour cultivars. Additionally, a QTL associated with vitreousness of grain was mapped in the short arm of chromosome 7A.
\end{abstract}

Keywords: bread wheat, physical properties of dough, substitution lines, recombinant lines, molecular markers

\footnotetext{
*Corresponding author; E-mail: quality@bionet.nsc.ru
} 


\section{Introduction}

Bread wheat is the most important food and basic bread crop of most countries in the world. A variety of products are manufactured from its grain and flour, but the most important of these is yeast bread. Its baking is possible due to the presence of gluten, which has a gas-holding ability. To obtain an excellent bread, the grain needs to have not only a high protein and gluten content but also must be able to give flour and dough with high physical properties (Kozmina 1959; Peña 2002). Previous studies using precise genetic stocks have found that in the ditelosomic lines 2AS, 4DL and 5DL of the low-quality Chinese Spring cultivar (CS), the flour strength is increased substantially (Maystrenko et al. 1973). The absence of one homologous chromosome 1D in the monosomic line of the high-quality Saratovskaya 29 (S29) cultivar leads to a significant deterioration in the rheological properties of dough, whereas the monosomic state for 4D chromosome significantly increases dough elasticity and strength (Arbuzova et al. 2001). The study of the technological properties of grain and flour in substitution lines has made it possible to identify the chromosomal localization and allelism at loci that control the biosynthesis of the protein components of gluten: gliadins and glutenins. These groups of proteins are controlled by polygenic loci located on the chromosomes of the first (Gli-1, Glu-1 and Glu-3) and the sixth (Gli-2) homoeological groups. Substitution of chromosome 1A carrying the null-allele of the Glu-A1 locus in low-quality varieties of CS and Diamant 2 by a homologous chromosome carrying a functional allele results in an improvement of the rheological properties of dough in the corresponding substitution lines (Payne et al. 1987; Pshenichnikova et al. 2006). The use of full sets of inter-varietal substitution lines show that the chromosomes of other homoeological groups are also involved in the genetic control of the technological properties of grain and flour (Kosmolak et al. 1980; Zemetra et al. 1987; Mansur et al. 1990). The development of DNA markers has been accompanied by the active production of many different mapping populations in bread wheat. This approach allows for the separation of complex quantitative traits into more simple loci. The presence of quantitative trait loci (QTLs) associated with quality parameters was shown both on the chromosomes of 1 and 6 homoeological groups as well as on other chromosomes of the wheat genome (Campbell et al. 2001; Groos et al. 2003; Sourdille et al. 2003; Huang et al. 2006; El-Feki et al. 2013; Echeverry-Solarte et al. 2015).

The spring wheat cultivar S29 is characterized by its exclusively high physical properties of flour and dough. Its main cultivation area is the arid steppe regions of Volga River, Kazakhstan and Siberia, but the cultivar retains its high quality in other growing conditions. Due to this, as well as its high ecological plasticity, the variety has been widely used in breeding, and its genotype is represented in pedigrees of many varieties (Likhenko 2008). The persistently high physical properties of flour and dough in S29 are not possible to explain solely using the combination of the favourable alleles of the gluten-encoding Glu-1 locus. According to Morgunov et al. (1990), this locus is represented by the alleles $G l u-A 1 b, G l u-B 1 c$ and Glu-D1a, which together give a moderate quality score ( 7 out of 10 possible). To determine the chromosomal localization of the responsible genetic factors, a complete set of substitution lines S29 (Yanetzkis Probat) 
(YP) was developed where the donor of individual chromosomes was a spring cultivar with average physical properties of flour and dough. The purpose of this work was to identify the chromosomes carrying the main loci that determine the high physical properties of flour in S29 and to map them using recombinant substitution lines genotyped with molecular markers.

\section{Materials and Methods}

\section{Genetic material}

The set of single chromosome substitution (SCS) lines S29 (YP) was obtained at the Institute of Cytology and Genetics SB RAS (Novosibirsk, Russia) (Gaidalenok et al. 1995). Pestsova et al. (2000) verified the accuracy of chromosome substitution using microsatellite markers. SCS lines for 6D and 7A chromosomes were removed from the experiment due to incorrect substitutions. Khlestkina et al. (2010) showed that the line S29 (YP 4D) carries a fragment of 7A chromosome from the donor. Therefore, this line was renamed as S29 (YP 4D*7A). The population of recombinant chromosome substitution double haploid (RCSDH) lines obtained by crossing the SCS line S29 (4D*7A) with the recipient S29 was used for mapping the quantitative traits loci (QTL).

\section{Growing conditions}

Sets of SCS lines and their parents were grown in Novosibirsk, Russia and in Sofia, Bulgaria. In Novosibirsk, the samples were grown in two replicates during spring sowing in the field of the Institute of Cytology and Genetics in 2005 and 2007. Plots were organized as randomized 1-meter rows with five rows per line and 50 grains in 1 row. In Sofia, the same lines and cultivars were grown in one replicate each during the spring sowing in 2007 and 2008. Each plot was $1.19 \mathrm{~m}^{2}$ (630 grains $\left./ \mathrm{m}^{2}\right)$ in size. Population RCSDH lines were grown in Novosibirsk in 2008 (102 lines) and 2009 (108 lines) according to the scheme described above.

\section{Methods of technological analysis of grain and flour}

Grain of lines and cultivars was assayed for nine technological parameters with using the methods recommended in Russia for crop variety testing (Anonymous 1988) with modifications for small samples of grain. Thousand-grain weight (TGW) was determined using the express method by weighing 100 grains. Grain vitreousness (\%) was determined visually after cutting 100 grains. Gluten content in grain (\%) was determined through hand washing of $1 \mathrm{~g}$ of whole meal. Particle size was defined using a PSH-4 device. The details of the analyses have been previously described (Shchukina et al. 2017). The physical properties of the flour and dough were studied using Chopin alveograph profiling. To measure properties, such as strength $\left(\mathrm{W}, \mathrm{J} \times 10^{-4}\right)$, tenacity $(\mathrm{P}, \mathrm{mm})$ extensibility $(\mathrm{L}, \mathrm{mm})$, and $\mathrm{P} / \mathrm{L}$ ratio, an alveograph with a $50 \mathrm{~g}$ mixer was used (method ISO-5530-4-91). 
Extraction of storage proteins was done using a method from Galili and Feldman (1983); for PAGE separation of protein components, the method described by Laemmli (1970) was used with modifications (Bulatova 1985).

\section{Statistical analysis}

Data from the four years was analysed for SCS. F-criterion was used for evaluating significant differences between the mean values of cultivars and lines (Dospekhov 1985). To evaluate the effects of genotype on milling parameters, gluten content in grain and the alveograph parameters, a two-way ANOVA was applied. The genotypes of S29, YP and the lines were considered as a fixed effect. Each year in Novosibirsk and Sofia was considered as a separate environment. The least significant difference (LSD) for mean values was calculated at $P<0.01 ; P<0.001$. For RCSDH population the mean value, range of variability and variation coefficient $(\%)$ were calculated for each environment.

\section{QTL analysis}

Linkage maps of the 4D and 7A chromosomes were constructed using the MAPMAKER 2.0 program (Lander et al. 1987). Genotyping data for GWM and WMC markers on the chromosome 4D and 7A maps were available from Khlestkina et al. (2010). The QTL analysis was carried out by employing QTX (Manly et al. 2001). QTX expresses the quality of a QTL assignment in the form of a likelihood ratio statistic (LRS). Experiment-wise threshold values were calculated by performing 1,000 permutations of the phenotypic data. When identifying associations of traits with molecular markers, QTLs were considered that exceeded the highly significant LRS level.

\section{Results}

Average data of parental cultivars and SCS lines for milling parameters, gluten content and physical properties of dough are presented in Table S1*. The gluten content in the grain of donor cultivar YP was significantly lower than in S29. Only substitution for the 3D chromosome of S29 for the homologous regions from YP resulted in a significant increase in the trait. Milling traits did not show significant variability among lines and environments.

The recipient S29 constantly showed high values of physical dough parameters in all years and environments, while in the donor, YP, average values of flour strength, dough tenacity and $\mathrm{P} / \mathrm{L}$ ratio were almost twice lower than in S29 (Table S1). According to the classification standards used in Russia to characterize varieties for baking qualities (Anonymous 1988; Berkutova 1991), S29 can be classified as a strong-flour wheat and YP as a valuable wheat. Tenacity was the most variable physical parameters among the SCS lines. The lines with 1A, 1B, 1D, 2A, 3A, 3B, 4A, 4D*7A, 5B, 6B substitutions all showed significantly lower means compared with the recipient. Only one line, with the

*Further details about the Electronic Supplementary Material (ESM) can be found at the end of the article. 
3B substitution, showed a significantly higher extensibility. The $\mathrm{P} / \mathrm{L}$ ratio decreased in the two lines with $3 \mathrm{~B}$ and $4 \mathrm{D} * 7 \mathrm{~A}$ substitutions. Three lines with $1 \mathrm{D}, 4 \mathrm{D} * 7 \mathrm{~A}$ and $6 \mathrm{~B}$ substitutions significantly decreased flour strength. In the two first lines, the value of the trait was comparable to that of the low-quality donor (Table S1). The greatest deterioration of the physical properties of dough, which was reproduced from year to year, was observed in the lines with the replacement of $1 \mathrm{D}$ and $4 \mathrm{D} * 7 \mathrm{~A}$ chromosomes of the high-quality recipient. According to the analysis of gluten proteins, several subunits belonging to lowmolecular weight glutenins were missing from the line S29 (YP 1D) (Fig. S1). The line S29 (YP 4D*7A) had the same gluten protein composition as in the recipient (Figure S1). This line, however, stably and under all conditions showed the lowest physical properties of flour and dough, even lower than that of the donor. This line was chosen to develop a mapping population. Average data on six technological parameters of the lines, parental cultivars and the initial substitution line S29 (YP 4D*7A) are presented in Table S2. Again, the donor cultivars and the line demonstrated low values of tenacity and dough strength comparing to the recipient S29. Comparable average means and range of variability were detected among RCSDH lines in both environments for thousand-grain weight and vitreousness. However, the physical parameters of the flour and dough had different
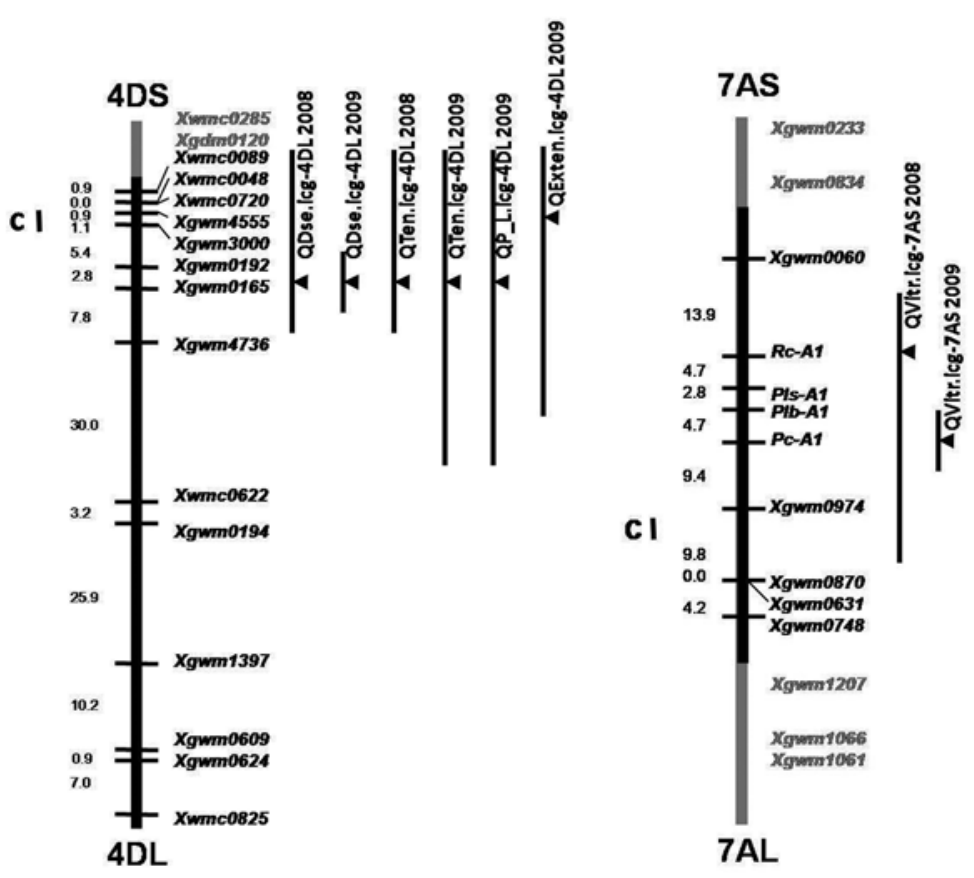

Figure 1. Genetic linkage maps of wheat chromosomes 4DS and 7AL showing QTL for dough strength (QDse. $i c g-4 D L)$, tenacity (QTen.icg-4DL), extensibility (QExten.icg-4DL), P/L ratio $\left(Q P \_L . i c g-4 D L\right)$ and vitreousness (QVitricg-7AS) from RCSDH S29 (YP 4D*7A) population grown at Novosibirsk in 2008 and 2009. Black vertical bars indicate intervals with highly significant likelihood ratio statistics (LRS) values. Black triangles indicate maximum LRS values for QTLs. C - centromere; Xgwm, Xgdm and Xwmc - wheat microsatellite loci 
variabilities. Dough strength was not affected much by the environment. The average of the other three traits differed between the two years as well as the ranges of variability. In 2009 , dough of the lines was less extensible. Nevertheless, variation coefficients were comparable in both years (Table S2).

Phenotypic data were integrated into the molecular linkage maps of 4D and 7A chromosomes (Fig. 1). Eight statistically significant major loci were found. Six and two of them were mapped to chromosomes 4D and 7A, respectively. The results of interval mapping are presented in Figures S2-5. The statistical descriptions are shown in Table 1. Two loci QTen.icg-4DL and two loci QDse.icg-4DL associated with tenacity and dough strength were mapped to the marker Xgwm0165 in the long arm of 4D chromosome. In both years, they were mapped precisely to that single marker and S29 was the donor of high dough strength and tenacity. The $Q P \_$L.icg-4DL locus for the trait of dough elasticity $(\mathrm{P} / \mathrm{L}$ ratio) was mapped at the same position only in 2009 , with high values coming from S29. The QExten.icg-4DL locus associated with dough extensibility was mapped near the marker Xgwm4555 on the long arm, proximal to Xgwm0165. The higher values were inherited from YP. The studied RCSDH lines were also recombinant for a part of chromosome 7A (Khlestkina et al. 2010). On its short arm, two loci QVitr.icg-7AS were mapped that were associated with grain vitreousness (Fig. 1; Fig. S5; Table 1). In 2008, the locus was mapped to the gene $R c-A 1$ and in 2009 to the region of the gene $P c-A 1$. The marker genes are situated $12,1 \mathrm{cM}$ from one another in the short arm of 7A chromosome (Fig. 1). The donor of increased vitreousness values was YP.

Table 1. The major loci (QTLs) for technological parameters of grain and flour mapped in the population S29 (YP 4D*7A)

\begin{tabular}{|c|c|c|c|c|c|c|c|}
\hline $\begin{array}{c}\text { Technological } \\
\text { parameters }\end{array}$ & QTL name & $\begin{array}{l}\text { Chromo- } \\
\text { some }\end{array}$ & Year & LRS* & $\begin{array}{l}\text { The marker } \\
\text { nearest to the } \\
\text { maximal LRS* }\end{array}$ & $\begin{array}{c}\text { Parental allele } \\
\text { increasing } \\
\text { the trait }\end{array}$ & $\begin{array}{c}\text { Input in } \\
\text { phenotypic } \\
\text { variance, \% }\end{array}$ \\
\hline \multirow{2}{*}{ Tenacity, P } & QTen.icg-4DL & $4 \mathrm{D}$ & 2008 & 20.0 & Xgwm0165 & S29 & 18 \\
\hline & QTen.icg-4DL & $4 \mathrm{D}$ & 2009 & 30.6 & Xgwm0165 & S29 & 25 \\
\hline Extensibility, L & QExten.icg-4DL & $4 \mathrm{D}$ & 2009 & 23.7 & Xgwm4555 & YP & 20 \\
\hline $\mathrm{P} / \mathrm{L}$ ratio & $Q P \_L . i c g-4 D L$ & $4 \mathrm{D}$ & 2009 & 33.8 & Xgwm0165 & S29 & 27 \\
\hline \multirow{2}{*}{ Flour strength } & QDse.icg- $4 D L$ & $4 \mathrm{D}$ & 2008 & 22.4 & Xgwm0165 & S29 & 20 \\
\hline & QDse.icg-4DL & $4 \mathrm{D}$ & 2009 & 14.3 & Xgwm0165 & S29 & 12 \\
\hline \multirow{2}{*}{$\begin{array}{l}\text { Vitreousness } \\
\text { of grain }\end{array}$} & QVitr.icg-7AS & $7 \mathrm{~A}$ & 2008 & 20.2 & $R c-A 1$ & YP & 18 \\
\hline & QVitricg-7AS & $7 \mathrm{~A}$ & 2009 & 10.8 & $P c-A 1$ & YP & 10 \\
\hline
\end{tabular}

*LRS - likelihood ratio statistic. 


\section{Discussion}

The study of the mechanisms of the formation of various technological parameters of grain and flour in wheat as well as detection of the responsible loci is a problem throughout the world. It has been shown that many chromosomes carry genetic factors that affect various quality traits (McIntosh et al. 2013). The role of individual groups of gluten proteins, such as high- and low-molecular weight glutenins, in the determination of flour and dough physical properties has been studied in great detail (Rogers et al. 1989; Branlard et al. 2001; Cornish et al. 2006; Khlestkina et al. 2016).

The recipient cultivar S29 has exceptional physical properties of its dough regardless of the growing conditions. Despite the fact that it was obtained in 1957, it is still retained in the Russian State register of breeding achievements (http://reestr.gossort.com/reestr/ sort/4900049). The donor of the individual chromosomes showed substantially lower flour strength, tenacity and $\mathrm{P} / \mathrm{L}$ ratio under all four conditions. During the study of physical properties of dough in the set of single chromosome substitution lines S29 (YP), two chromosomes, 1D and 4D*7A, were identified in which substitution negatively affected flour strength, dough tenacity and $\mathrm{P} / \mathrm{L}$ ratio, with values reaching or below the donor. S29 is known to carry the $a(2+12)$ allele of Glu-D1 locus (Morgunov et al. 1990). This allele is not favourable for gluten quality (Cornish et al. 2006). Although it is not known which allele of low-molecular weight glutenins S29 carries, we found differences in their composition between donor and SCS for chromosome 1D (Fig. S1). This might be the reason for the deterioration of the physical properties of dough in this line. The effect of chromosome 1D dosage on these traits in different cultivars has been previously described (Welsh and Hehn 1964; Maystrenko et al. 1973; Arbuzova et al. 2001).

The line S29 (YP 4D*7A) was selected to develop a mapping population for two reasons. First, according to the average data for four years of research it had flour strength, tenacity and $\mathrm{P} / \mathrm{L}$ ratio that was even lower than that of the donor cultivar. Second, the possible impact of glutenin and gliadin variability on the quality, as in the case of 1D chromosome was excluded. Eight main QTLs responsible for technological parameters were mapped using RCSDH lines S29 (4D*7A) (Fig. 1, Table 1). The two main loci QTen.icg-4DL and QDse.icg-4DL associated with tenacity and flour strength were mapped on the long arm of chromosome 4D in the region of marker Xgwm0165. The loci QExten.icg-4DL and $Q P P_{-}$.icg-4DL were mapped close to this position for only one year of growing. Nevertheless, they introduced $20 \%$ and $27 \%$ phenotypic diversity, respectively. It should be noted that no such loci for the physical properties of dough have been found in mapping populations outside of Russia. Perhaps this is because the S29 cultivar of the Russian spring wheat gene pool was not involved in crossings outside Russia. Meanwhile, Morozova et al. (2016), when studying technological parameters of grain in the old and modern spring wheat cultivars of Russia, identified the association of alveograph parameters with the region of the markers Xgwm 165c and Xgwm 165a, b on chromosome 4B and 4D, respectively.

The major locus QVitricg-7AS associated with variability for grain vitreousness was mapped in the interval of genes $R c 1-P c l$ controlling anthocyanin pigmentation of co- 
leoptile and culm on the short arm of 7A chromosome. Thus far, loci involved in the formation of the endosperm structure of wheat grain have been described on the long arm of chromosomes of the homoeological group 7. For example, Wilkinson et al. (2008), using the mapping populations Spark $\times$ Rialto, Shamrock $\times$ Shango and Malacca $\times$ Charger, mapped the Pinb-A2 locus in chromosome 7AL. Chen et al. (2010) and Geng et al. (2012) identified several allelic variants of Pinb-2 in the distal regions of long arms of the same chromosomes using CS aneuploids and substitution lines of durum wheat Langdon.

\section{Conclusion}

With the help of recombinant substitution double haploid lines, the region on 4D chromosome was shown in the strong-flour cultivar S29, with the microsatellite locus Xgwm0165 to be associated with the unique physical properties of flour and dough. The detected loci are not related to the gluten protein composition. They may be recommended to breeders for selection of strong-flour cultivars. In addition, a QTL associated with vitreousness of grain was mapped in the short arm of chromosome 7A.

\section{Acknowledgements}

The work was supported by the ICG project (No 0324-2018-0018). Wheat lines used are supported in IC\&GSB RAS collection "GenAgro" (Novosibirsk, Russia). The authors declare no conflict of interest.

\section{References}

Anonymous. 1988. Method of state variety testing of crops. Gosagroprom. Moscow, Russia. (in Russian).

Arbuzova, V.S., Ermakova, M.F., Popova, P.K. 2001. Studies of monosomic lines of cv. Saratovskaya 29 on productivity and grain technological properties. EWAC Newsletter (Proceedings of the 11th EWAC Conference, Novosibirsk). pp. 80-82.

Berkutova, N.S. 1991. The methods of evaluation and formation of grain quality. Rosagropromizdat. Moscow, Russia. pp. 10-22. (in Russian)

Branlard, G., Dardevet, M., Saccomano, R., Lagoutte, F., Gourdon, J. 2001. Genetic diversity of wheat storage proteins and bread wheat quality. Euphytica 119:59-67.

Bulatova, K.M. 1985. The study of glutenin component composition of wheat. Vestnik sel'skokhozyastvennykh nauk Kazakhstana. 4:37-39. (In Russian)

Campbell, K.G., Finney, P.L., Bergman, C.J., D. Gualberto, G., Anderson, J.A., Giroux, M.J., Siritunga, D., Zhu, J., Gendre, F., Roue, C., Verel, A., Sorrells, M.E. 2001. Quantitative trait loci associated with milling and baking quality in a soft $\times$ hard wheat cross. Crop Sci. 41:1275-1285.

Chen, F., Xu, H.-X., Zhang, F.-Y., Xia, X.-C., He, Z.-H., Wang, D.-W., Dong, Z.-D., Zhan, K.-H., Cheng, X.-Y., Cui, D.-Q. 2010. Physical mapping of puroindoline b-2 genes and molecular characterization of a novel variant in durum wheat (Triticum turgidum L.). Mol. Breeding 28:153-161. DOI 10.1007/s11032010-9469-2.

Cornish, G.B., Békés, F., Eagles, H.A., Payne, P.I. 2006. Prediction of dough properties for bread wheats. In: Gliadin and Glutenin. The unique balance of wheat quality. Eds.: C. Wrigley, F. Békés, W. Bushuk. AACC International, pp. 243-279.

Dospekhov, B.A. 1985. The technique of field experiment (with the basic statistical processing of experimental results). Agropromizdat. Moscow, Russia. (in Russian) 
Echeverry-Solarte, M., Kumar, A., Kianian, Sh., Simsek, S., Alamri, M.S., Mantovani, E.E., McClean, P.E., Deckard, E.L., Elias, E., Schatz, B., Xu, S.S., Mergoum, V. 2015. New QTL alleles for quality-related traits in spring wheat revealed by RIL population derived from supernumerary $\times$ non-supernumerary spikelet genotypes. Theor. Appl. Genet. 128:893-912.

El-Feki, W.M., Byrne, P.F., Reid, S.D., Lapitan, N.L.V., Haley, S.D. 2013. Quantitative trait locus mapping for end-use quality traits in hard winter wheat under contrasting soil moisture levels. Crop Sci. 53:1953-1967.

Gaidalenok, R.F., Khrabrova, M.A., Litkovskaya, N.P., Kovaleva, N.M. 1995. Development and use of lines with substituted chromosomes in Saratovskaya 29 / Yanetzkis Probat. EWAC Newsletter (Proceedings of 9th EWAC Conference, Gatersleben-Wernigerode). pp. 128-131.

Galili, G., Feldman, M. 1983. Genetic control of endosperm proteins in wheat. Variation in high molecular weight glutenin and gliadin subunits of Triticum aestivum. Theor. Appl. Genet. 66:77-86.

Geng, H., Beecher, B.S., He, Zh., Morris, C.F. 2012. Physical mapping of puroindoline b-2 genes in wheat using 'Chinese Spring' chromosome group 7 deletion lines. Crop Sci. 52:2674-2678.

Groos, C., Robert, N., Brevas, E., Charmet, G. 2003. Genetic analysis of grain protein-content, grain yield and thousand-kernel weight in bread wheat. Theor. Appl. Genet. 106:1032-1040.

Huang, X.Q., Cloutier, S., Lycar, L., Radovanovic, N., Humphreys, D.G., Noll, J.S., Somers, D.J., Brown, P.D. 2006. Molecular detection of QTLs for agronomic and quality traits in a doubled haploid population derived from two Canadian wheats (Triticum aestivum L.). Theor. Appl. Genet. 113:753-766.

Khlestkina, E.K., Roder, M.S., Pshenichnikova, T.A., Börner, A. 2010. Functional diversity at Rc (red coleoptile) locus in wheat (Triticum aestivum L.). Mol. Breeding. 25:125-132.

Khlestkina, E.K., Pshenichnikova, T.A., Usenko, N.I., Otmakhova, Yu.S. 2016. Prospective applications of molecular genetic approaches to control technological properties of wheat grain in the context of the "grain - flour - bread" chain. Vavilovskii Zhurnal Genetiki i Selektsii = Vavilov Journal of Genetics and Breeding, 20(4):511-527.

Kozmina, N.P. 1969. Grain. Moscow, Kolos Publisher, 368 p. (in Russian)

Kosmolak, F.G., Larson, R.I., McKenzie, H. 1980. Milling and baking quality of Rescue $\times$ Cadet reciprocal substitution lines. Can. J. Plant Sci. 60:1333-1341.

Laemmli, U.K. 1970. Cleavage of structural proteins during the assembly of the head of bacteriophage T4. Nature 227:680-685.

Lander, E.S., Green, P., Abrahamson, J., Barlow, A., Daly, M.J., Lincoln, S.E., Newburg, L. 1987. MAPMAKER: an interactive computer package for constructing primary genetic linkage maps of experimental and natural populations. Genomics. 1:174-181.

Likhenko, I.V. 2008. The use of world and local varieties gene pool of spring bread wheat in breeding (to 50 years of release of the cultivar Saratovskaya 29). Rastenievodstvo i selektsiya (Crop production and Breeding). 1:25-30.

Manly, K.F., Cudmore, R.H., Meer, J.M. 2001. Map manager QTX, cross-platform software for genetic mapping. Mamm. Genome. 12:930-932.

Mansur, L.M., Qalset, C.O., Kasarda, D.D., Morris, R. 1990. Effects of "Cheyenne" chromosomes on milling and baking quality in "Chinese Spring" wheat in relation to glutenin and gliadin storage protein. Crop Sci. 30:593-602.

Maystrenko, O.I., Troshina, A.V., Ermakova, M.F. 1973. Chromosomal arm location of genes for flour quality in wheat using ditelosomic lines. Proc. 4th Intern. Wheat Genetics Symp., Missouri Agr. Exptl. Station. pp. 51-56.

McIntosh, R.A., Yamazaki, Y., Dubcovsky, J., Rogers, J., Morris, C., Appels, R., Xia, X.C. 2013. Catalogue of Gene Symbols for Wheat. 12th International Wheat Genetics Symposium, 8-13 September, Yokohama, Japan.

Morgunov, A.I., Rogers, W.J., Sayers, E.J., Metakovsky, E.V. 1990. The high-molecular-weight glutenin subunit composition of Soviet varieties. Euphytica 51:41-52.

Morozova, E.V., Pshenichnikova, T.A., Simonov, A.V., Shchukina, L.V., Chistyakova, A.K., Khlestkina, E.K. 2016. A comparative study of grain and flour quality parameters among Russian bread wheat cultivars developed in different historical periods and their association with certain molecular markers. EWAC 
Newsletter (Proceedings of the 16th International EWAC Conference, 24-29 May 2015, Lublin, Poland). pp. 49-56.

Payne, P.I., Seekings, J.A., Worland, A.J., Holt, L.M. 1987. Allelic variation of glutenin subunits and gliadins and its effect on bread-making quality in wheat: analysis of F5 progeny from Chinese Spring $\times$ Chinese Spring (Hope 1A). J. Cereal Sci. 6:103-118.

Peña, R.J. 2002. Wheat for bread and other foods. BREAD WHEAT. Improvement and Production, Rome, 2002, FAO.

Pestsova, E., Salina, E.A., Börner, A., Korzun, V., Maystrenko, O.I., Röder, M.S. 2000. Microsatellites confirm the authenticity of inter-varietal chromosome substitution lines of wheat (Triticum aestivum L.). Theor. Appl. Genet. 101:95-99.

Pshenichnikova, T.A., Ermakova, M.F., Popova, R.K. 2006. Technological properties of grain and flour in bread wheat lines with inter-varietal substitution of chromosomes of 1 and 6 homoeological groups. Sel'skokhozya'ctvennaya biologia (Agricultural biology). 1:57-62.

Rogers, W.J., Payne, P.I., Harinder, H. 1989. The HMW glutenin subunits and gliadin composition of Germangrown wheat varieties and their relationship with bread-making quality. Plant Breeding 103:89-100.

Sourdille, P., Cadalen, T., Guyomarc'h, J., Snape, J.W., Perretant, M.R., Charmet, G., Boeuf, C., Bernard, S., Bernard, M. 2003. An update of the Courtot $\times$ Chinese Spring intervarietal molecular marker linkage map for the QTL detection of agronomic traits in wheat. Theor. Appl. Genet. 106:530-538.

Shchukina, L.V., Pshenichnikova, T.A., Chistyakova, A.K., Khlestkina, E.K., Börner, A. 2017. Properties of grain, flour and dough in bread wheat lines with Aegilops markgrafii introgressions. Cereal Research Communications 45:296-306.

Welsh, J.R., Hehn, E.K. 1964. The effect of chromosome 1D on hexaploid wheat flour quality. Crop Sci. 4:320-323.

Wilkinson, M., Wan, Y., Tosi, P., Leverington, M., Snape, J., Mitchell, R.A.C., Shewry, P.R. 2008. Identification and genetic mapping of variant forms of puroindoline b expressed in developing wheat grain. J. Cereal Sci. 48:722-728.

Zemetra, R.S., Morris, R., Mattern, P.P., Seip, L. 1987. Gene location for flour quality in winter wheat using reciprocal chromosome substitutions. Crop Sci. 27:677-681.

\section{Electronic Supplementary Material (ESM)}

Electronic Supplementary Material (ESM) associated with this article can be found at the website of CRC at https://akademiai.com/loi/0806

Electronic Supplementary Table S1. Average values of grain and flour technological characteristics among the inter-varietal single chromosome substitution lines S29 (YP) for four seasons of growing in Russia and Bulgaria

Electronic Supplementary Table S2. Average values of grain and flour technological characteristics among the substitution recombinant double haploid lines, parental cultivars and single chromosome substitution line intervarietal single chromosome substitution lines S29 (YP 4D*7A)

Electronic Supplementary Figure S1. SDS-PAGE of storage proteins in the parental genotypes and substitution lines with lowered dough strength. 1 - S29, 2 - S29 (YP 4D*7A), 3 - S29 (YP 1D), 4 -YP. Dotted and solid arrows show on the subunits of S29 absent in 1D substitution

Electronic Supplementary Figure S2. Interval mapping of the dough strength on wheat chromosome 4D in 2008 (left) and in 2009 (right). LRS - likelihood ratio statistic, AE - additive effect. The most right vertical bar indicates highly significant LRS threshold. Xgwm and Xwm - microsatellite loci 
Electronic Supplementary Figure S3. Interval mapping of the tenacity on wheat chromosome 4D in 2008 (left) and in 2009 (right). LRS - likelihood ratio statistic, AE - additive effect. The most right vertical bar indicates highly significant LRS threshold. Xgwm and Xwm - microsatellite loci

Electronic Supplementary Figure S4. Interval mapping of the extensibility on wheat chromosome 4D (left) and $\mathrm{P} / \mathrm{L}$ ratio (right) in 2009. LRS - likelihood ratio statistic, $\mathrm{AE}$ - additive effect. The most right vertical bar indicates highly significant LRS threshold. Xgwm and Xwm - microsatellite loci

Electronic Supplementary Figure S5. Interval mapping of the vitreousness on wheat chromosome 7A in 2008 (left) and in 2009 (right). LRS - likelihood ratio statistic, AE - additive effect. The most right vertical bar indicates highly significant LRS threshold. Xgwm and Xwm - microsatellite loci 